\title{
A STUDY OF BACTERIAL PATHOGENS AND THEIR ANTIBIOTIC SUSCEPTIBILITY PROFILE FROM COMMUNITY-ACQUIRED AND HOSPITAL-ACQUIRED URINARY TRACT INFECTIONS
}

\author{
Chithra Jayaprakash1, Meenakshi Sumangala Bai
}

${ }^{1}$ Associate Professor, Department of Microbiology, MOSC Medical College, Kolencherry.

2 Professor, Metro Scans and Laboratory, Medical College, Thiruvananthapuram.

\section{ABSTRACT}

\section{BACKGROUND}

Urinary Tract Infections (UTI) are a leading health problem affecting millions of people every year. In the hospital setting, it is a very important reason for increased hospital stay, increased morbidity and mortality. Multiple antibiotic resistance among uropathogens has compounded the problem. Community-and hospital-acquired UTIs differ with regard to aetiology, epidemiology, and antibiotic susceptibility profile.

\section{AIM}

The study aimed at identifying the bacterial aetiology of UTIs, and finding out the antibiotic susceptibility pattern of the isolates. Based on these results, a comparison was made between community- and hospital-acquired cases of UTIs.

\section{METHODS}

The study was mainly a hospital-based one. A total of 550 urine samples were collected from patients having symptoms of UTI. Of these, 275 were from community-acquired cases and 275 from hospital-acquired cases. The samples collected were inoculated using the calibrated loop, incubated aerobically, isolates identified by standard biochemical reactions and antibiotic susceptibility testing performed.

\section{RESULTS}

Of the 550 samples processed 191 (34.73\%) were culture positive, 108 (56.54\%) were from community-acquired and 83 $(43.46 \%)$ from hospital-acquired cases; $97.7 \%$ of the isolates were Gram-negative whereas the Gram-positive isolates were only $2.3 \%$. The most frequently isolated pathogen was Escherichia coli $(50.8 \%)$, Klebsiella pneumoniae ranking second (26.7\%). The highest incidence of antibiotic resistance was for Ampicillin (77.38\%) and the lowest recorded for Norfloxacin (53.57\%) among the first-line agents.

\section{CONCLUSION}

Dissemination of the data on uropathogens and their antibiotic susceptibility profile to wards and intensive care units will aid in control of this infection to a large extent.

\section{KEYWORDS}

Urinary Tract Infections, Bacterial Pathogens, Antibiotic Susceptibility.

HOW TO CITE THIS ARTICLE: Jayaprakash C, Bai MS. A study of bacterial pathogens and their antibiotic susceptibility profile from community-acquired and hospital-acquired urinary tract infections. J. Evolution Med. Dent. Sci. 2016;5(27):1400-1404, DOI: $10.14260 /$ jemds/2016/330

\section{INTRODUCTION}

Urinary Tract Infection (UTI) refers to any type of urothelial inflammatory response resulting from bacterial invasion of the urinary tract. UTIs are one of the commonest bacterial infections.(1) affecting millions of people each year.

It also contributes significantly to the economic burden by increased hospital stay, increased morbidity and mortality. The incidence is highest among women. About $20-50 \%$ of women will suffer a clinical episode during their lifetime. It is the commonest hospital-acquired infection world-wide.

Financial or Other, Competing Interest: None.

Submission 15-02-2016, Peer Review 11-03-2016,

Acceptance 17-03-2016, Published 04-04-2016.

Corresponding Author:

Dr. Chithra Jayaprakash,

Associate Professor,

Department of Microbiology,

MOSC Medical College,

Kolenchery-682311.

E-mail: chithrasc@yahoo.com

DOI: $10.14260 /$ jemds $/ 2016 / 330$
Bacteriological culture of urine samples is recommended for outpatients with recurrent UTIs, treatment failures or have complicated UTIs and for inpatients who develop UTIs.(1) Studies infer Gram negative bacteria to be the major uropathogens of which Escherichia coli is the commonest pathogen causing community- and hospital-acquired UTIs.(2) Community- and hospital-acquired UTIs differ with respect to aetiology, epidemiology and antibiotic susceptibility pattern. Hospital strains are found to be more drug resistant than community strains. But studies have cautioned the leakage of multidrug resistant strains into the community as well, which is an alarming concern. Easy availability of antibiotics such as Ampicillin, Norfloxacin and Nitrofurantoin is one major contributor of drug resistance in India. The extensive use of antimicrobial agents have led to an alarming increase in antibiotic resistance world-wide.(3) Uropathogens producing Extended Spectrum $\beta$-Lactamases (ESBLs) and Amp C $\beta$ Lactamases are on the rise.(4) Now, CTX-M-15 ESBLs are becoming more common worldwide. Multidrug Resistant (MDR) uropathogens make treatment options very limited to 
antimicrobial agents like carbapenems, colistin and fosfomycin.

Hence, all these issues have stimulated us in doing this particular study that aimed at isolation, identification and antibiotic susceptibility testing of bacterial pathogens from hospital-acquired and community-acquired cases of UTI.

\section{MATERIALS AND METHODS}

This hospital-based prospective study was conducted in the Department of Microbiology for a period of 9 months; 550 urine samples from patients with clinically diagnosed UTI were collected for the study. Of these, 275 were collected from wards for hospital-acquired cases and 275 from outpatient clinics for community-acquired cases. Adults of both sexes with symptoms of UTI were considered for the study. Only cases of significant bacteriuria were included in the study. Urine samples whose microscopy showed presence of squamous epithelial cells were excluded from the study. The age, sex, brief history of the illness, previous history of UTI and details regarding Diabetes Mellitus were recorded. The patients were instructed properly regarding the method of collection of clean catch, midstream urine samples. For catheterized samples, the catheter tubing was clamped off to allow collection of freshly voided urine. The port was disinfected with $70 \%$ alcohol and urine aspirated through the port with a sterile needle and syringe. All the urine samples were collected in sterile, wide-mouthed, leak-proof containers.

Macroscopic and microscopic examinations were performed. Direct wet mount and Gram smear preparations of the samples were examined. All the samples were processed uncentrifuged and undiluted. Blood agar and MacConkey agar were used for primary isolation of the bacterial pathogens. Mueller Hinton agar was used for antibiotic susceptibility testing. A calibrated loop designed to deliver $0.002 \mathrm{~mL}$ of urine was used for inoculation. The charged loop was spread in a line across the diameter of the plate, crossing the first inoculum streak several times to produce isolated colonies. The inoculated plates were incubated at $37^{\circ} \mathrm{C}$ for $24 \mathrm{hrs}$.

The isolated bacterial pathogens were identified by standard biochemical reactions and their antibiotic susceptibility testing performed by Stokes disc diffusion method. The antibiotics selected for the study were Ampicillin, Gentamicin, Cephalexin, Co-trimoxazole, Nalidixic acid, Norfloxacin, Amikacin, Cefotaxime, Ciprofloxacin, Netilmicin, Ceftazidime and Cloxacillin.

\section{STATISTICAL ANALYSIS}

Prevalence for culture positivity in the samples were calculated. Prevalence of individual aetiological agents among the culture positive samples and of antibiotic resistance were also calculated.

\section{RESULTS}

A total of 550 urine samples were processed during the study period. Of these, $330(60 \%)$ were those of females and 220 $(40 \%)$ were those of males. Of the 330 samples of females, 120 (36.4\%) samples yielded significant bacterial growth. Of the 220 samples of males, 71 (32.3\%) samples were culture positive (Table 1 ).

$108(56.54 \%)$ of the 191 culture positive cases in the study were community-acquired and 83 (43.46\%) hospitalacquired (Table 2).
Among the 275 hospital-acquired cases of UTI selected for the study, 165 were catheterized (60\%) and 110 were not catheterized $(40 \%)$. Majority of the pathogens causing hospital-acquired UTI were isolated from catheterized patients $(70,84.3 \%)$.

Gram negative bacilli accounted for the majority of the culture positive cases (96.33\%) and Escherichia coli (E. coli) was the most common uropathogen isolated; (50.8\%) - (Table 3 and Bar Diagram 1). It was also the most common organism isolated from community-acquired cases $(68.5 \%)$ and the second most frequently isolated bacterium from hospitalacquired cases (27.7\%). Klebsiella pneumoniae (K. pneumoniae) was the most frequently isolated pathogen from hospital-acquired cases (37.3\%) and the second most commonly isolated one from community-acquired cases (18.5\%). Pseudomonas aeruginosa (P. aeruginosa-12.05\%), Acinetobacter lwoffii (A. lwoffi-12.05\%), Enterobacter cloacae (E. cloacae-4.8\%) and Proteus mirabilis (P. mirabilis-6.02\%) were the other Gram negative bacteria isolated more from hospital-acquired cases in this study (Table 4).

Only 7 Gram positive bacterial isolates $(3.66 \%)$ were recovered during the study period. These included Staphylococcus aureus (S. aureus-2.8\%), Staphylococcus saprophyticus (S. saprophyticus-1.9\%), Enterococcus faecalis (E. faecalis-0.93\%) and Streptococcus pyogenes (S. pyogenes$0.93 \%)$.

Among the 1st line drugs (Ampicillin, Gentamicin, Cephalexin, Co-trimoxazole, Nalidixic acid and Norfloxacin), Gentamicin had the highest percentage of susceptibility for $\mathrm{E}$. coli $(54.6 \%)$, Norfloxacin ranking second (52.6\%). But K. pneumoniae was most susceptible to Norfloxacin (37.3\%), followed by Nalidixic acid (35.3\%) (Table 5).

Pseudomonas aeruginosa was most susceptible to Amikacin (50\%) and Ceftazidime (50\%) and least susceptible to Gentamicin (18.8\%). The susceptibility to Netilmicin and Ciprofloxacin each were $25 \%$.

21 isolates of E. coli (21.65\%), 27 K. pneumoniae (52.94\%), 8 A. lwoffi (80\%) and 2 E. cloacae (40\%) were tested for 2 nd line antibiotics as they were resistant to the first line drugs. E. coli was most susceptible to Ciprofloxacin (52.38\%) and least susceptible to Cefotaxime (0\%) (Table 6). The multidrug resistant isolates included $10 \mathrm{E}$. coli, 23 Klebsiella pneumoniae, 6 Acinetobacter spp. and 1 Enterobacter spp.; 35 of these 40 multidrug resistant isolates were isolated from hospital-acquired cases (87.5\%). The antibiotic susceptibility pattern of the Gram positive bacterial isolates are given below. All the S. aureus isolates were susceptible to cephalexin and cloxacillin, but only $66.7 \%$ were susceptible to Ampicillin and Gentamicin. All the S. saprophyticus isolates, the E. faecalis, and the S. pyogenes were susceptible to Ampicillin.

E. coli and K. pneumoniae being the two most common bacteria isolated from the urine samples, were subjected to a comparative study with respect to community-acquired and hospital-acquired UTI cases. Of the first line antibiotics tested, E. coli was most susceptible to Gentamicin, both in communityacquired $(64.9 \%)$ as well as hospital-acquired cases $(21.7 \%)$ (Bar Diagram 2). The K. pneumoniae obtained from the community-acquired cases were more susceptible to Norfloxacin (75\%) than the hospital-acquired cases $(13 \%)$ (Bar Diagram 3). 


\section{DISCUSSION}

In our study of the 550 urine samples obtained, only 191 yielded significant bacteriuria. The reason for the low isolation rate in our study might be due to prior antibiotic therapy; $36.4 \%$ of females and $32.3 \%$ of males in the study were culture positive. The male-female ratio of prevalence of UTI in the study was 1:1.5. According to the study done by Al-Badr et al., the male-female ratio of prevalence of UTI is 1:8.(5) UTIs are more common in females than in males. The short urethra in females greatly predisposes them to infection of the urinary tract by the ascending route.(6) Of the 191 culture positive cases, 108 (56.54\%) were community-acquired and 83 (43.46\%) hospital-acquired. Among the 275 hospital-acquired cases of clinically diagnosed UTI, 165 were catheterized (60\%). According to Nicolle LE.(7) $70-80 \%$ of health-care associated infections are attributable to the use of an indwelling urethral catheter. Catheter-associated UTI can be minimized if the duration of catheterization is less than 2 weeks and good aseptic care and sterile closed drainage system are maintained.

The material with which the catheters are made is also an important factor. $(8,9,10)$ Majority of the samples yielded Gram-negative bacilli (184, 96.34\%). This is in accordance with a study done by Ahmed $\mathrm{N}$ et al. (82\%).(11) E. coli was the most frequently isolated pathogen $(50.8 \%)$ followed by $\mathrm{K}$. pneumoniae $(26.7 \%)$ in our study. Shevade et al.(2) has reported $\mathrm{E}$. coli to be the most frequently isolated communityas well as hospital-acquired uropathogen (48.67\%). Neto JAD et al.(12) in their study came to the finding that E. coli was the most common pathogen isolated from UTI cases (58.4\%) followed by Klebsiella spp. (8.5\%). Hanna-Wakim et al.(13) in her study reports $\mathrm{E}$. coli to be the most frequently isolated pathogen $(79.4 \%)$ followed by K. pneumoniae (7.9\%). Ahmed NH et al.(11) Toval F. et al.(14) and Tasbakan MI et al.(15) also came to the finding that $\mathrm{E}$. coli is the most frequently isolated uropathogen from community- and hospital-acquired UTI cases. All the 7 Gram-positive isolates were recovered from community-acquired cases. In a study by Nerurkar A et al.(16) $23.21 \%$ of the bacterial isolates were Gram-positive of which S. aureus accounted for 92.3\%. Other Gram-negative organisms isolated were A. lwoffi, E. cloacae and P. mirabilis. In recurrent UTIs, especially in the presence of structural abnormalities of the urinary tract, the relative frequency of infection caused by these organisms increases greatly.(17)

Among the 1st line antibiotics tested, the lowest incidence of bacterial resistance was for Norfloxacin (53.57\%). The organisms were most resistant to Ampicillin (77.38\%). Ferry and Burman in their study have recorded the lowest incidence of bacterial resistance to Cotrimoxazole.(18) The percentage resistance of $\mathrm{E}$. coli to Norfloxacin in hospital patients was $82.6 \%$ and that in community patients was only $36.5 \%$. In a study by Baral P et al.(19) the highest percentage of resistance to first-line antibiotics among Gram-negative bacteria were found for amoxicillin (57.7\%), Cotrimoxazole (53.6\%) and norfloxacin (36.4\%). Another study by UzunovicKamberovi S. (20) showed low resistance of E. coli to Norfloxacin (5.4\%) and high resistance rate to Ampicillin (72.6\%) and Cotrimoxazole (50.2\%). Of the 40 multidrug resistant isolates obtained $35(87.5 \%)$ were recovered from hospital-acquired UTI cases, which highlights several issues (inappropriate use of antibiotics, non-standard doses for insufficient duration etc.) that lead to emergence of antibiotic resistance. Baral P. et al.(19) reports a high incidence of multidrug resistance in hospital-acquired UTI cases (85\%).

\section{CONCLUSION}

In our study, 550 urine samples were processed of which 191 yielded significant bacterial growth. Maximum number of isolates were obtained from females. More isolates were recovered from community-acquired UTI cases than from hospital-acquired UTI cases. This might be due to the fact that hospital inpatients receive a variety of antibiotics, which make it quite impossible to isolate the causative organism. Antibiotic resistance and recurrent UTIs are also common in the hospitalacquired UTI patients. E. coli was the most common organism isolated from CA-UTI cases and K. pneumoniae was the most common one from HA-UTI cases. The hospital strains were more drug resistant than the community strains. Multidrug resistance was more common among $\mathrm{K}$. pneumoniae isolates.

More than $95 \%$ of UTIs are caused by a single bacterial species.(16) Amikacin, Ciprofloxacin and Cefotaxime were used only if the organisms were found resistant to the 1st line antibiotics. It is essential for the clinician to update the changing bacterial aetiology of UTI and the antibiotic susceptibility profile in an area. The emergence of antibiotic resistance among uropathogens is a grave health issue. Strengthening the infection control measures and antibiotic policies can curb this impending catastrophe to a great extent.

\begin{tabular}{|c|c|c|c|}
\hline Sex & $\begin{array}{c}\text { No. of Urine } \\
\text { Samples } \\
\text { Tested }\end{array}$ & $\begin{array}{c}\text { No. of } \\
\text { Culture } \\
\text { Positives }\end{array}$ & $\begin{array}{c}\text { Percentage } \\
\text { (\%) }\end{array}$ \\
\hline Male & 220 & 71 & 32.3 \\
\hline Female & 330 & 120 & 36.4 \\
\hline $\begin{array}{c}\text { Both } \\
\text { Sexes }\end{array}$ & 550 & 191 & 34.7 \\
\hline \multicolumn{3}{|c|}{ Table 1: Relationship between Gender } \\
and Culture Positivity \\
\hline
\end{tabular}

\begin{tabular}{|c|c|c|c|c|}
\hline $\begin{array}{c}\text { Total } \\
\text { No. of Culture } \\
\text { Positives }\end{array}$ & \multicolumn{2}{|c|}{$\begin{array}{c}\text { Community- } \\
\text { acquired } \\
\text { Isolates }\end{array}$} & \multicolumn{2}{|c|}{$\begin{array}{c}\text { Hospital- } \\
\text { acquired } \\
\text { Isolates }\end{array}$} \\
\hline \multirow{2}{*}{191} & No: & Percentage & No: & Percentage \\
\cline { 2 - 5 } & 108 & $56.54 \%$ & 83 & $43.46 \%$ \\
\hline \multicolumn{4}{|c|}{ Table 2: Distribution of Bacterial Isolates } \\
among Community and Hospital-Acquired Cases \\
\hline
\end{tabular}

\begin{tabular}{|c|c|c|}
\hline Bacterial Isolate & $\begin{array}{l}\text { Total No. } \\
(n=191)\end{array}$ & $\begin{array}{l}\text { Percentage } \\
(\%)\end{array}$ \\
\hline Escherichia coli & 97 & 50.8 \\
\hline Klebsiella pneumoniae & 51 & 26.7 \\
\hline Pseudomonas aeruginosa & 16 & 8.4 \\
\hline Acinetobacter lwoffi & 10 & 5.2 \\
\hline Enterobacter cloacae & 5 & 2.6 \\
\hline Proteus mirabilis & 5 & 2.6 \\
\hline Staphylococcus aureus & 3 & 1.57 \\
\hline Staphylococcus saprophyticus & 2 & 1.05 \\
\hline Enterococcus faecalis & 1 & 0.52 \\
\hline Streptococcus pyogenes & 1 & 0.52 \\
\hline \multicolumn{3}{|c|}{$\begin{array}{c}\text { Table 3: Bacterial Pathogens Isolated } \\
\text { During the Study Period }\end{array}$} \\
\hline
\end{tabular}




\begin{tabular}{|l|c|c|c|c|}
\hline \multicolumn{1}{|c|}{ Bacterial Isolate } & \multicolumn{2}{c|}{$\begin{array}{c}\text { Community- } \\
\text { Acquired } \\
\text { Cases } \\
\text { (n=108) }\end{array}$} & \multicolumn{2}{c|}{$\begin{array}{c}\text { Hospital- } \\
\text { Acquired } \\
\text { cases } \\
(\mathbf{n = ~ 8 3 )}\end{array}$} \\
\hline \multirow{2}{*}{ 1) E. coli } & No. & $\%$ & No. & $\%$ \\
\hline & 74 & 68.50 & 23 & 27.70 \\
\hline 2) Klebsiella pneumoniae & 20 & 18.50 & 31 & 37.30 \\
\hline 3) P. aeruginosa & 6 & 5.50 & 10 & 12.05 \\
\hline 4) A. lwoffi & - & - & 10 & 12.05 \\
\hline
\end{tabular}

\begin{tabular}{|c|c|c|c|c|}
\hline 5) E. cloacae & 1 & 0.93 & 4 & 4.80 \\
\hline 6) P. mirabilis & - & - & 5 & 6.02 \\
\hline 7) S. aureus & 3 & 2.80 & - & - \\
\hline 8) S. saprophyticus & 2 & 1.90 & - & - \\
\hline 9) E. faecalis & 1 & 0.93 & - & - \\
\hline 10) S. pyogenes & 1 & 0.93 & - & - \\
\hline
\end{tabular}

\begin{tabular}{|c|c|c|c|c|c|c|}
\hline Bacterial isolate & Amp. & Genta. & Ceph. & Co-tri & Nal. & Nor \\
\hline E. coli & $33 \%$ & $54.60 \%$ & $51.50 \%$ & $32 \%$ & $35 \%$ & $52.60 \%$ \\
\hline Klebsiella pneumoniae & $0 \%$ & $33.30 \%$ & $29.40 \%$ & $31.40 \%$ & $35.30 \%$ & $37.30 \%$ \\
\hline E. cloacae & $0 \%$ & $0 \%$ & $0 \%$ & $0 \%$ & $0 \%$ & $60 \%$ \\
\hline A. lwoffi & $0 \%$ & $30 \%$ & $0 \%$ & $30 \%$ & $20 \%$ & $20 \%$ \\
\hline P. mirabilis & $0 \%$ & $20 \%$ & $40 \%$ & $0 \%$ & $20 \%$ & $60 \%$ \\
\hline Table 5: Antibiotic Susceptibility Pattern of the Gram-Negative Urinary Bacterial Isolates to First-Line Agents \\
\hline
\end{tabular}

Amp- Ampicillin, Genta-Gentamicin, Ceph- Cephalexin, Co-tri- Co-trimoxazole, Nal- Nalidixic acid, Nor- Norfloxacin

\begin{tabular}{|c|c|c|c|c|c|c|c|}
\hline \multirow{2}{*}{ Organism } & \multirow{2}{*}{ Total No. } & \multicolumn{2}{|c|}{ Ciprofloxacin } & \multicolumn{2}{c|}{ Amikacin } & \multicolumn{2}{c|}{ Cefotaxime } \\
\cline { 3 - 8 } & & No. & $\mathbf{\%}$ & No. & \% & No. & \% \\
\hline E. coli & 21 & 11 & 52.38 & 2 & 9.52 & 0 & 0 \\
\hline Klebsiella pneumoniae & 27 & 3 & 11.1 & 1 & 3.70 & 1 & 3.70 \\
\hline A. lwoffi & 8 & 0 & 0 & 2 & 25 & 0 & 0 \\
\hline E. cloacae & 2 & 1 & 50 & 0 & 0 & 0 & 0 \\
\hline Table 6: Antibiotic Susceptibility Pattern of Resistant Bacterial Isolates to Second-Line Agents \\
\hline
\end{tabular}

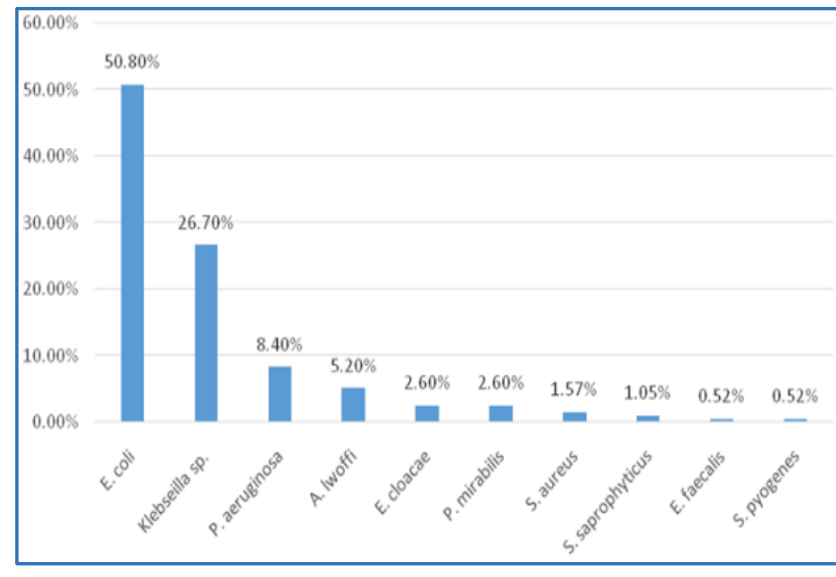

Bar Diagram 1: Bacterial Pathogens Isolated During the Study Period

COMPARISON OF PERCENTAGE ANTIBIOTIC SUSCEPTIBILITY PATTERN OF COMMUNITY-AND HOSPITAL-ACQUIRED E.COLIISOLATES TO FIRST-LINE AGENTS

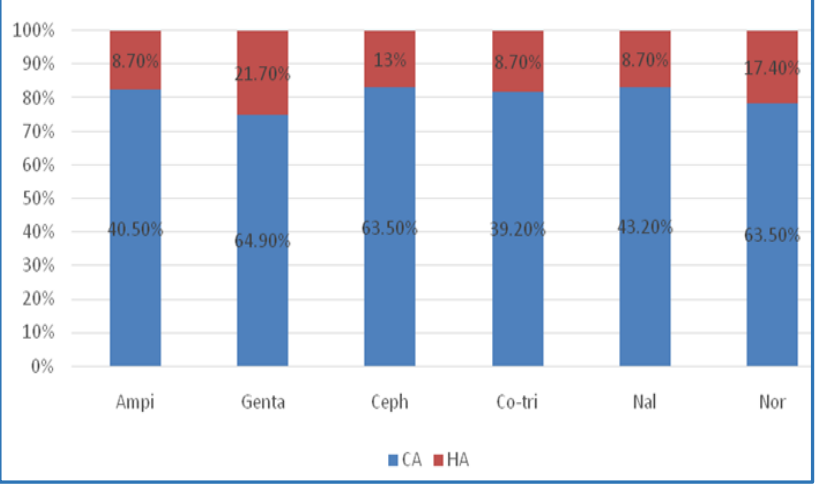

Bar Diagram 2

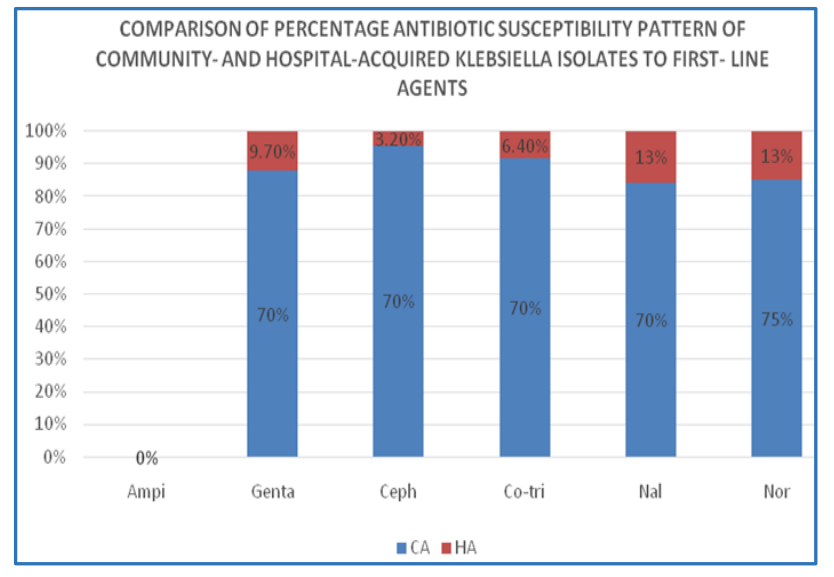

Bar Diagram 3

\section{REFERENCES}

1. Wilson ML, Gaido L. Laboratory diagnosis of urinary tract infections in adult patients. Clin Infect Dis 2004;38(8):1150-1158.

2. Shevade SU, Agrawal GN. Study of community and nosocomial uropathogens and their drug resistance. National Journal of Community Medicine 2013;4(4):647652.

3. Kumar MS, Lakshmi V, Rajagopalan R. Occurrence of extended spectrum beta-lactamases among enterobacteriaceae spp. Isolated at a tertiary care institute. Indian J Med Microbiol 2006;24(3):208-211.

4. Sasirekha B. Prevalence of ESBL, ampC $\beta$-lactamases and MRSA among uropathogens and its antibiogram. EXCLI Journal 2013;12:81-88.

5. Al-Badr A, Al-Shaikh G. Recurrent urinary tract infections management in women. Sultan Qaboos University Med J 2013;13(3):359-367. 
6. Urinary tract infections. www.rochester.edu/uhs.

7. Nicolle LE. Catheter associated urinary tract infections. Antimicrob Resist Infect Control 2014;3:23.

8. Talja M, Korpela A, Jarvi K. Comparison of urethral reaction to full silicone, hydrogel-coated and siliconised latex catheters. Br J Urol 1990;66(6):652-657.

9. Gabriel MM, Mayo MS, May LL, et al. In vitro evaluation of the efficacy of a silver-coated catheter. Curr Microbiol 1996;33(1):1-5.

10. Johnson JR, Delavari P, Azar M. Activities of a nitrofurazone containing urinary catheter and a silver hydrogel catheter against multidrug resistant bacteria characteristic of catheter-associated urinary tract infection. Antimicrobial Agents Chemotherapy 1999;43(12):2990-2995.

11. Ahmed NH, Hussain T, Biswal I. Comparison of etiological agents and resistance patterns of the pathogens causing community acquired and hospital acquired urinary tract infections. J Glob Infect Dis 2014;6(3):35-136.

12. Neto JAD, Martins ACP, DaSilva LDM, et al. Communityacquired urinary tract infections: etiology and bacterial susceptibility. Acta Cr Bras 2003;18(5).

13. Hanna-Wakim RH, Ghanem ST, El Helour MW, et al. Epidemiology and characteristics of urinary tract infections in children and adolescents. Front cell Infect Microbiol 2015;5(45):1-8.

14. Toval F, Kohler CD, Vogel U, et al. Characterization of escherichia coli isolates from hospital inpatients or outpatients with urinary tract infection. J Clin Microbiol 2014;52(2):407-418.
15. Tasbakan MI, Durusoy R, Pullukcu H, et al. Hospitalacquired urinary tract infections point prevalence in Turkey: differences in risk factors among patient groups. Annals of Clinical Microbiology and Antimicrobials 2013;12:31.

16. Nerurkar A, Solanky P, Naik SS. Bacterial pathogens in urinary tract infection and antibiotic susceptibility pattern. Journal of Pharmaceutical and Biomedical Sciences 2012;21(12):1-3.

17. Sobel JD, Kaye D. Urinary tract infections. In: Mandell GL, Bennett JE, Dolin R, eds. Principles and Practice of Infectious diseases, New York: Churchill Livingstone, 2010; 7 thedition:957-985.

18. Ferry S, Burman LG. Urinary tract infection in primary health care in Northern Sweden bacteriology in relation to clinical and epidemiological factors. Scand J Prim Health Care 1987;5(4):233-240.

19. Baral P, Neupane S, Marasini BI, et al. High prevalence of multidrug resistance in bacterial uropathogens from Kathmandu, Nepal. Bio Med Central Research Notes 2012;5:38.

20. Uzunovic-Kamberovi S. Antibiotic resistance of coliform organisms from community-acquired urinary tract infections in zenica-doboj canton, bosnia and herzegovina. Journal of Antimicrobial Chemotherapy 2006;58:344-348. 